\title{
Biomarkers of gliomas and their impact on diagnosis, prognosis, and treatment
}

\author{
Argenis F. Álvarez-Guerrero and Rubén López-Revilla* \\ Molecular Biology Division, Instituto Potosino de Investigación Científica y Tecnológica. San Luis Potosí, San Luis Potosí, Mexico
}

\begin{abstract}
Tumors of the central nervous system (CNS) are due to the abnormal growth of cells in the brain or spinal cord that can become malignant and spread by metastases. Gliomas are the most frequent malignant tumors of the CNS, characterized by their heterogeneity and invasiveness. The high lethality of gliomas is due, among other causes, to the low efficacy of current treatments. The few biomarkers effective for the classification, prognosis, and treatment of the various types of gliomas are a useful tool for their management. New markers are currently being sought to make a more accurate diagnosis and for their potential as therapeutic targets. In this review, we describe the traditional biomarkers and other biomarkers that could be used to improve the diagnosis, prognosis, and treatment of gliomas.
\end{abstract}

Key words: Glioma. Biomarker. Diagnosis. Prognosis. Treatment.

\section{Biomarcadores de gliomas y su impacto en el diagnóstico, pronóstico y tratamiento}

\section{Resumen}

Los tumores del sistema nervioso central (SNC) se deben al crecimiento anormal de las células de los tejidos del encéfalo o la médula espinal y pueden malignizarse y diseminarse por metástasis. Los gliomas son los tumores malignos más frecuentes del SNC y se caracterizan por su heterogeneidad e invasividad. La elevada letalidad de los gliomas se debe, entre otras causas, a la baja eficacia de los tratamientos actuales. Los escasos biomarcadores útiles para la clasificación, el pronóstico y el tratamiento de los diversos tipos de gliomas representan una herramienta útil para su manejo. Actualmente se buscan nuevos marcadores para hacer el diagnóstico más preciso y por su potencial como blancos terapéuticos. En esta revisión describimos los biomarcadores tradicionales y algunos otros que podrían mejorar el diagnóstico, pronóstico y tratamiento de los gliomas.

Palabras clave: Glioma. Biomarcador. Diagnóstico. Pronóstico. Tratamiento.

Primary tumors of the central nervous system (CNS) are a complex and heterogeneous group with wide diversity in diagnosis, prognosis, and treatment. Among more than 100 histological types of primary CNS tumors, the most frequent are the encephalic ones, which account for $85-90 \%$ of all diagnosed tumors ${ }^{1}$.

Meningiomas and pituitary tumors are the most incident primary brain tumors (53.9\%) followed by

\section{Correspondence:}

*Rubén López-Revilla E-mail: rlopez@ipicyt.edu.mx
Available online: 11-02-2021

Date of reception: 05-05-2020 Date of acceptance: 23-06-2020 DOI: 10.24875/RMN.20000029
Rev Mex Neuroci. 2021;22(1):22-29

www.revmexneurociencia.com 1665-5044/ @ 2020 Academia Mexicana de Neurología A.C. Published by Permanyer. This is an open access article under the CC BY-NC-ND license (http://creativecommons.org/licenses/by-nc-nd/4.0/). 


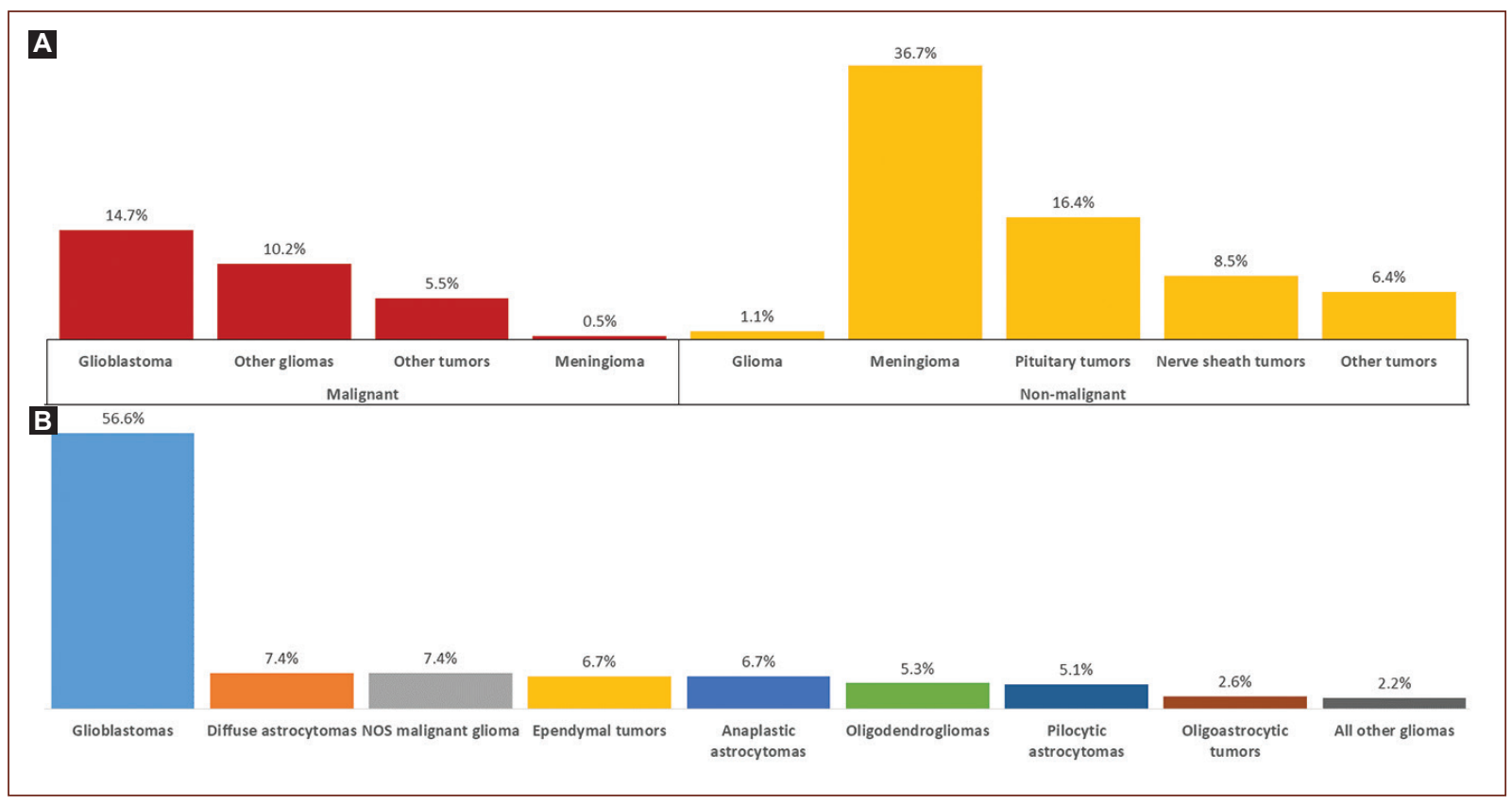

Figure 1. Incidence of malignant tumors of the central nervous system (CNS) and histological types of gliomas. A: incidence of CNS tumors; $69.1 \%$ non-malignant, 30.9\% malignant. B: histological types of gliomas. (Ostrom et al. ${ }^{2}$ ).

glioblastomas. Glioblastomas are the most incident primary CNS malignant tumors (57.3\%). The less frequent gliomas are oligoastrocitomas, and children are the most vulnerable group for brain tumor incidence ${ }^{2}$.

The vast majority of gliomas do not spread to other parts of the body but only to other parts of the brain or the spinal $\operatorname{cord}^{3}$.

\section{Gliomas}

Gliomas are a category of primary malignant tumors of the CNS with various subtypes of heterogeneous characteristics ${ }^{4}$. The molecular mechanism of glioma formation is not clear ${ }^{4,5}$, it is considered that these tumors originate from progenitor glial cells or stem cells with glial properties. For these reason, different types of gliomas are named according to the cells from which they seem to have arisen ${ }^{6}$.

Gliomas are the most frequent malignant tumors of the CNS (Fig. 1A), and their aggressiveness is mainly due to their invasiveness. The inefficacy of treatments for the wide variety of glioma subtypes implies an unfavorable prognosis ${ }^{7}$, reflected in their high mortality rates $^{8}$.

Glioblastoma multiforme (GBM) is the most lethal and most common glioma subtype (Fig. 1B). Its high mortality rate derives from the inefficacy of the few available treatments ${ }^{9}$. Whilst low-grade gliomas have a low mortality rate, their highly epileptogenic characteristic seizures have a drastic impact on the patient's life quality $^{10}$.

\section{Classification of gliomas}

\section{Morphological}

Gliomas are classified as diffuse or non-diffuse by the World Health Organization (WHO). Non-diffuse types have circumscribed growth patterns, and Grades II through IV are assigned to the diffuse ones according to their severity ${ }^{11}$.

In the case of diffuse gliomas, the diagnosis based on the histological characteristics starts with the identification of the morphology and cell type from which they seem to have originated (Fig. 2) ${ }^{12}$. Some highgrade neoplasms have aggressive behaviors, reflected on the cell damage due to the tumor growth, making the diagnosis largely dependent on the experience of the analyst ${ }^{11}$.

The WHO classification of gliomas based only on morphological and histological characteristics is subjective and inconsistent, since many histologically identical diffuse gliomas differ in progression, response to treatment, and outcome ${ }^{13}$. 


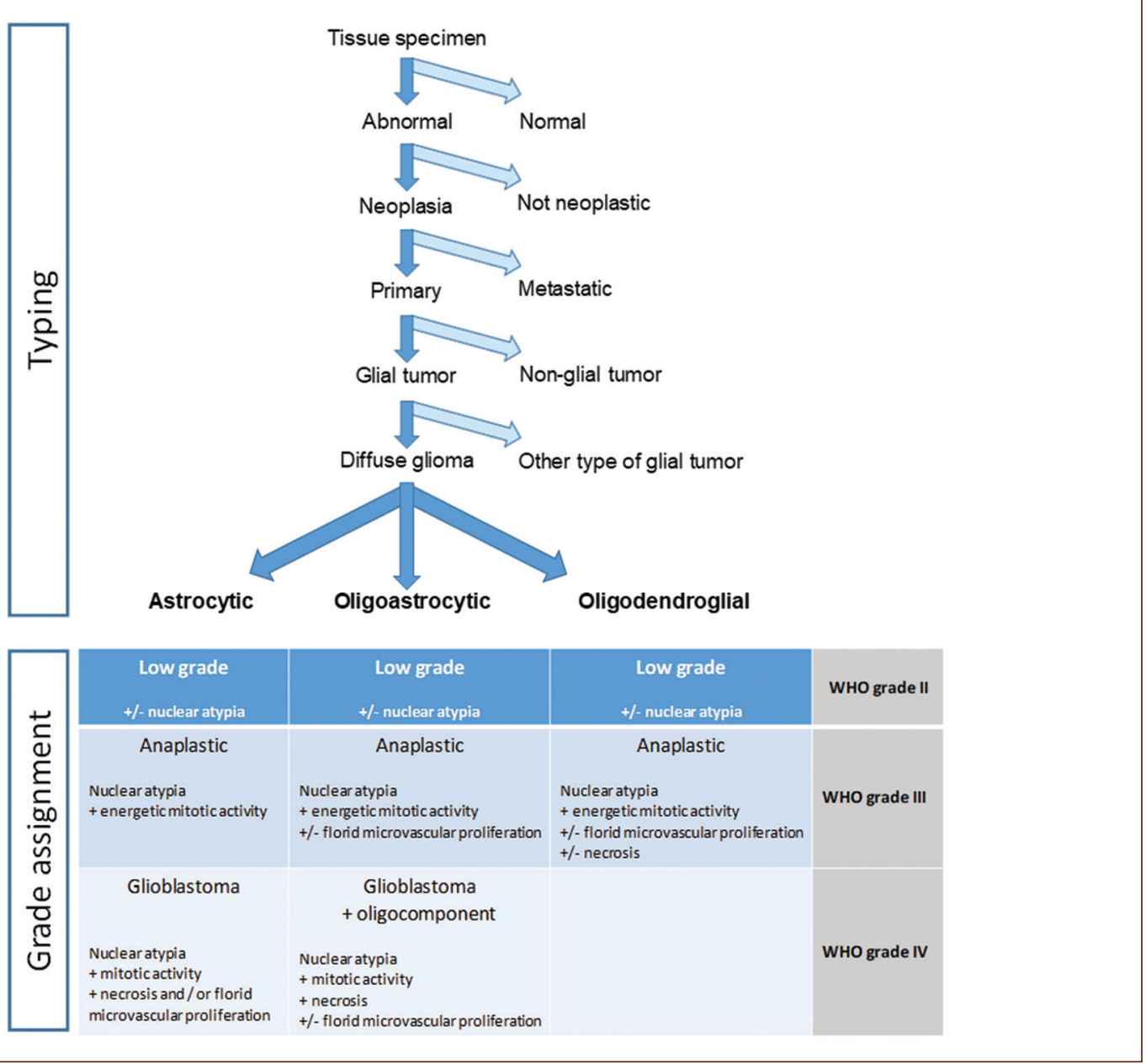

Figure 2. Algorithm for typing, grade assignment, and microscopic classification of diffuse gliomas. Decision tree for typing and grading of gliomas by histological methods, including microscopic criteria for the classification of diffuse gliomas (adapted from Wesseling et al. ${ }^{6}$.

Advances in molecular marker identification and image processing technologies have led to a more precise classification that has improved the accuracy of the diagnosis and prognosis of CNS tumors that complement the morphological and histological characteristics $^{14}$. The fourth edition of the WHO CNS tumor classification included for the first time a criterion based on the presence/absence of two molecular markers in gliomas (Fig. 3): the isocitrate dehydrogenase (IDH) gene mutation and the $1 p / 19 q$ codeletion ${ }^{15}$.

$I D H 1$ and IDH2 mutations are found in astrocytomas, oligodendrogliomas, secondary glioblastomas, and in Grades II and III oligoastrocytomas, whereas Grades II and III diffuse gliomas with wild-type IDH genes have molecular characteristics and behavior of glioblastomas ${ }^{11}$.

The presence of both an $I D H$ mutation and the $1 p / 19 q$ codeletion is characteristic of diffuse oligodendroglioma-type gliomas. In contrast, an IDH mutation without 1p/19q codeletion identifies astrocytoma-type gliomas ${ }^{11}$.

These new criteria have helped to integrate the diagnosis, characterization, surgical interventions, prognosis, and multiple options of new glioma treatments ${ }^{10,14,16}$.

\section{Magnetic resonance and basic biomarkers}

A biomarker is "a characteristic that is objectively measured and evaluated as an indicator of normal biological processes, pathogens, or pharmacological responses to a therapeutic intervention"17. Many biomarkers correspond to molecular characteristics that provide information for the diagnosis and prognosis of diseases. In the field of CNS tumors, biomarkers represent a means to understand the molecular pathways and deregulation mechanisms related to these tumors 


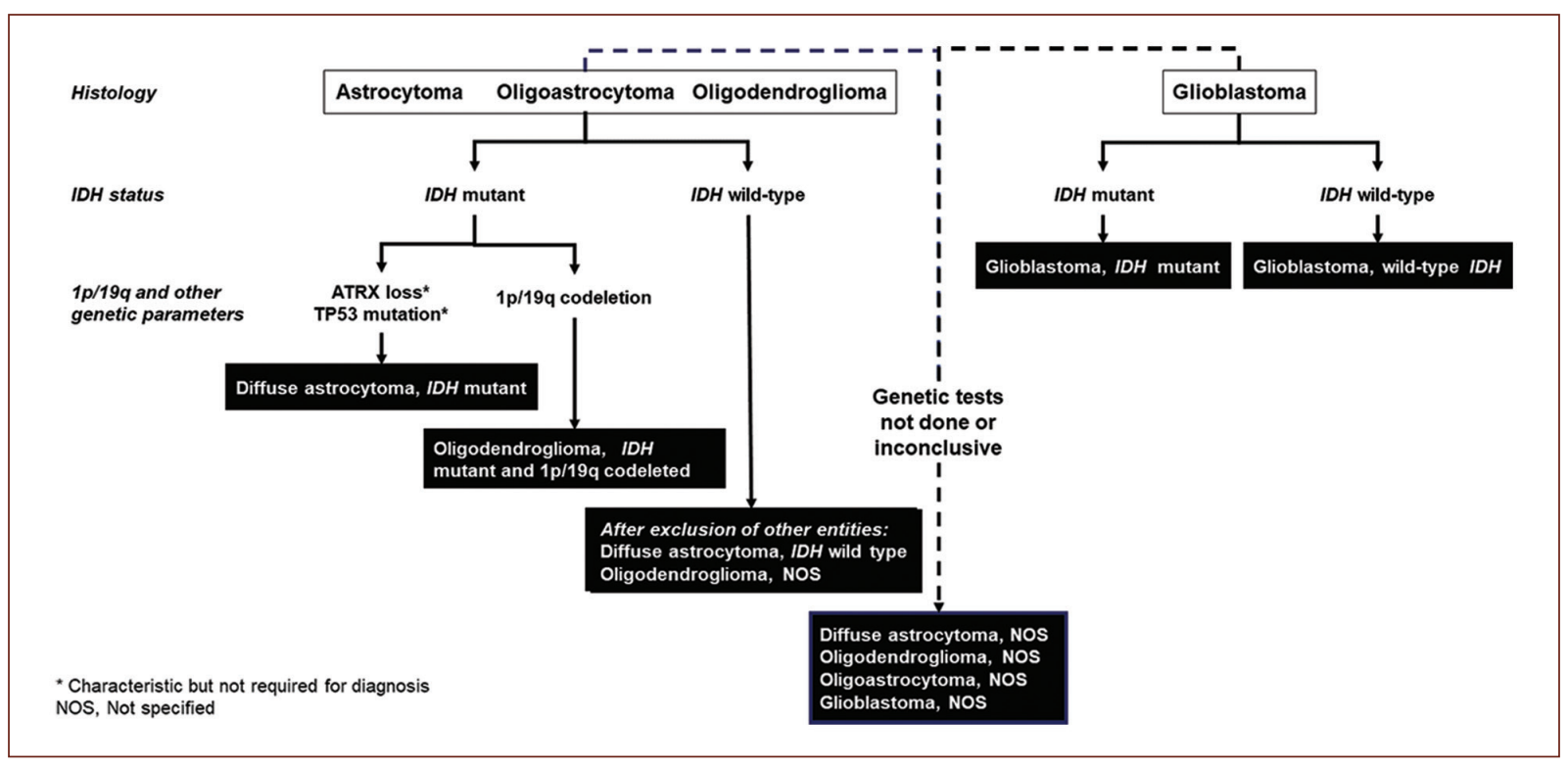

Figure 3. Simplified algorithm for glioma classification based on molecular biomarkers. The World Health Organization classification of gliomas uses this algorithm based on molecular biomarkers (adapted from Louis et al.30).

that even have the potential to be extended to other cancer types ${ }^{12,16}$.

The incorporation of a criterion based on the molecular characteristics of gliomas greatly served to redefine tumor subtypes in the WHO classification ${ }^{11,13}$. This is why molecular tools are currently used for the diagnosis of gliomas besides traditional histology and imaging methods ${ }^{4}$.

In the field of neuro-oncology, machine learning methods based on magnetic resonance imaging (MRI) in conjunction with biomarkers outperform traditional statistical methods ${ }^{18}$.

The list of current biomarkers for human gliomas is limited and the search for new markers is relevant not only to improve diagnosis but also for the potential to find new therapeutic targets for various glioma types ${ }^{19}$.

MRI, basic and additional biomarkers for the diagnosis, prognosis, and treatment of gliomas (Table 1) are described in this and the following sections.

\section{MRI}

MRI is a routine procedure for the diagnosis of gliomas that gives a structural overview of the location, detailed anatomy, and pathological information of the tumor and allows the acquisition of additional physiological details in conjunction with other advanced techniques. Many studies to determine the molecular profiles, histological grade, and prognosis of gliomas are based on magnetic resonance images acquired when the tumor is first detected ${ }^{18}$.

Biomarkers in conjunction with MRI help to improve the classification, prognosis, and choice of glioma treatment $^{9}$. An example is a radiomics-based method with three-dimensional MRIs obtained with specialized equipment allowing non-invasive estimation of the IDH1 gene mutation status ${ }^{16}$.

\section{IDH mutations}

IDH genes are traditional glioma biomarkers. Mutations in the loci encoding the human isoforms 1 (IDH1) and 2 (IDH2) are associated with better prognosis and therapeutic response of patients with gliomas ${ }^{16,20}$. In low-grade gliomas and few secondary glioblastomas have been identified, the single nucleotide polymorphism in codon $132(\mathrm{R} 132 \mathrm{H})$, which determines the amino acid changes from arginine to histidine in the IDH1 isoform, as well as in the 172 codon analog of the IDH2 isoform ${ }^{20}$.

Besides the fact that IDH1 and IDH2 gene mutations are relevant diagnosis and prognosis biomarkers, they are also associated with the incidence of pre-operative seizures in patients with low-grade gliomas ${ }^{10}$. In conjunction with the analysis of IDH1/2 mutations, two more markers are used for a more accurate diagnosis of gliomas: the chromosome codeletion $1 \mathrm{p} / 19 \mathrm{q}^{21}$ and the methylation of the $\mathrm{O}^{6}$-methylguanine-DNA-methyltransferase (MGMT) gene promoter ${ }^{13}$. 
Table 1. Basic and additional glioma biomarkers

\begin{tabular}{|c|c|c|c|c|}
\hline \multicolumn{2}{|l|}{ Biomarkers } & \multirow{2}{*}{$\begin{array}{l}\text { Types of gliomas } \\
\text { Diffuse astrocytoma } \\
\text { WHO (II-IV) }\end{array}$} & \multirow{2}{*}{$\begin{array}{l}\text { Use } \\
\text { Identify IDH mutant status }\end{array}$} & \multirow{2}{*}{$\begin{array}{c}\text { References } \\
16\end{array}$} \\
\hline Basic & Magnetic resonance imaging & & & \\
\hline & IDH1/2 mutation & WHO (II-III) & Favorable prognosis & 10 \\
\hline & MGMT promoter methylation & $\begin{array}{l}\text { Glioblastoma multiforme } \\
\text { WHO Grade IV }\end{array}$ & $\begin{array}{l}\text { Favorable prognosis } \\
\text { Chemotherapy sensitivity }\end{array}$ & 13 \\
\hline & $1 p / 19 q$ codeletion & Oligodendrogliomas & Favorable prognosis & 13 \\
\hline \multirow[t]{7}{*}{ Additional } & ATRX mutation & Anaplastic astrocytoma & Favorable prognosis & 21 \\
\hline & GFAP expression & Astrocytomas & Not a marker of lesser malignancy & 4 \\
\hline & SND1 overexpression & WHO Grades III-IV & $\begin{array}{l}\text { Unfavorable prognosis } \\
\text { Promotes RhoA expression Potential target }\end{array}$ & 24 \\
\hline & RhoA overexpression & WHO Grades III-IV & $\begin{array}{l}\text { Unfavorable prognosis } \\
\text { Promotes cell proliferation }\end{array}$ & 24,25 \\
\hline & TIP30 expression & WHO Grades III-IV & $\begin{array}{l}\text { Favorable prognosis } \\
\text { Suppress EGFR }\end{array}$ & 19,27 \\
\hline & EGFR mutation & WHO Grades IV & Unfavorable prognosis & 13 \\
\hline & LncRNAs H19, MALAT1, POU3F3 & WHO Grades II-IV & Unfavorable prognosis & 29 \\
\hline
\end{tabular}

Reviewing the IDH1/2 mutation status is a routine study for glioma classification ${ }^{13}$, complemented with non-invasive methods that detect the IDH status to quantify the patterns in various types of gliomas, mainly of low grade. An example is a non-invasive method that correlates MRI with the estimation of the IDH1 status in Grade II gliomas through segmentation, extraction of high-performance characteristics, selection, and classification of three-dimensional images through the use of radiomics. ${ }^{16}$

\section{MGMT gene promoter methylation}

The MGMT gene encodes a DNA repair protein whose expression is affected by epigenetic changes such as methylation, which induces silencing ${ }^{22}$.

MGMT gene promoter methylation is a favorable prognostic marker for patients with high-grade astrocytic gliomas and also predicts a favorable response to the chemotherapy of anaplastic gliomas and glioblastomas with wild-type IDH1/2 profiles, as well as glioblastomas in older adults ${ }^{13}$.

\section{$1 p / 19 q$ codeletion}

A marker widely used in the classification of gliomas is the codeletion or loss of the heterozygous $1 p / 19 q$ region, due to a centromeric translocation ${ }^{23}$. Glial tumors with this codeletion are defined as oligodendroglial tumors and have a favorable prognosis ${ }^{13}$.

\section{Additional biomarkers}

\section{Staphylococcal nuclease domain 1 (SND1)}

Overexpression of the SND1 protein is a common phenomenon in various malignant human tissues. SND1 promotes the malignant glioma phenotype through an epigenetic route that generates the topologic interaction of chromatin by promoting histone acetylation besides stimulating downstream transcription activation of the RhoA (Ras homolog family member $\mathrm{A}$ ) gene that encodes the GTPase 1 and promotes cell proliferation and invasiveness. SND1 and RhoA are, therefore, independent indicators of unfavorable prognosis of gliomas ${ }^{24}$.

Silencing the SND1 gene suppresses the proliferation and invasion of glioma cells, a finding indicating that the gene is not only a biomarker but a potential therapeutic target ${ }^{24}$.

\section{RhoA}

Overexpression of the RhoA protein has been associated with tumor cell proliferation and metasta$\operatorname{sis}^{25}$. The inclusion of RhoA as a non-favorable 
prognostic biomarker of high-grade gliomas derives from the fact that SND1 activates transcription of the RhoA gene in cultured glioma cells and that the RhoA protein regulates the expression of CCND1, CCNE1, CDK4, and CDKN1B genes and accelerates the $\mathrm{G} 1 / \mathrm{S}$ transition of the cell cycle that promotes proliferation ${ }^{16}$.

\section{Glial fibrillary acidic protein (GFAP)}

The GFAP, a classic astrocytoma marker, is used to determine glial differentiation associated with lesser malignancy and is currently in the clinical and experimental phase for other glioma subtypes. However, GFAP does not seem to be a good marker of lower malignancy and differentiation among astrocytoma subtypes, because it is not only expressed in mature astrocytes but also during the development of stem cells in the adult brain ${ }^{4}$.

GFAP has a large number of splicing variants and different expression ratios of the $\alpha$ and $\delta$ GFAP isoforms (GFAPS/ $\alpha$ ) may be found. A GFAPS/ $\alpha$ low expression ratio is associated with low-grade astrocytomas, whereas a high ratio is associated with high-grade astrocytomas $^{26}$. Quantification of the GFAP $\alpha$ and $\delta$ isoforms differentiates high- and low-grade astrocytomas and avoids confusing overall GFAP expression with less malignancy ${ }^{4,26}$.

\section{TIP30}

The TIP30 gene encodes the Tat30 interaction protein, a tumor suppressor protein involved in tumor cell growth, metastasis, and angiogenesis in various cancers $^{27}$. TIP30 regulates tumor formation and provides a clear prognosis to glioma patients ${ }^{19}$.

TIP30 expression correlates inversely with histological classification, pathological grade, tumor size, and epidermal growth factor receptor (EGFR) expression ${ }^{19}$. TIP30 expression levels decrease significantly in glioma tissue, and patients with positive TIP30 expression have greater survival and longevity than those with silenced TIP30 ${ }^{19}$.

In glioma cell cultures TIP30 decreases the expression of the EGFR and downstream associated kinase genes such as $E R K$ and $A K T$. These findings indicate that TIP30 could suppress oncogenesis and glioma progression and serve not only as a prognostic biomarker but also as a potential therapeutic target ${ }^{19}$.

\section{ATRX}

The ATRX gene encodes a protein essential for development, which regulates gene expression at the level of transcription by chromatin remodeling ${ }^{28}$.

ATRX gene mutation is a widely used biomarker for the classification of astrocytomas, and its loss is a favorable prognostic marker. ATRX loss and 1p/19q codeletion status have been used to reclassify anaplastic oligoastrocytomas. Tumors with ATRX loss have a course similar to that of anaplastic astrocytomas, whereas those with both ATRX loss and 1p/19q codeletion have a course similar to that of anaplastic oligodendrogliomas ${ }^{21}$.

\section{EGFR}

The EGFR gene mutation is a glioma biomarker because it cancels EGFR expression ${ }^{13}$ and correlates inversely with TIP30 overexpression ${ }^{19}$.

\section{Long non-coding RNAs (LncRNAs)}

LncRNAs are a class of non-protein-translated $\mathrm{RNAs}^{29}$. There is a high expression of LncRNAs participating in brain development under normal conditions and in various pathogenic processes that include glioma formation.

The association of LncRNAs with the initiation, differentiation, progression, recurrence, and characteristics of glioma progenitor stem cells makes them potential biomarkers for glioma subclassification, diagnosis, and prognosis. Knowledge of the key routes of LncRNAs for brain development can help to understand glioma formation and to find potential therapeutic targets 29 .

\section{Impact of biomarkers}

When a glioma is suspected, immediate actions are directed to obtain the MRI of the tumor and to confirm the diagnosis by biopsy. IDH status, MGMT promoter methylation, and $1 p / 19 q$ codeletion are the major biomarkers for tumor classification. The presence of wildtype $I D H$ is associated with poor prognosis, while $1 p / 19 q$ codeletion and MGMT promoter methylation are associated with favorable prognosis.

Since the aggressiveness of the various glioma types is variable, developing additional prognostic markers could improve patient management. The addition of SND1 could provide key elements for the 
classification of high-grade (III-IV) gliomas ${ }^{24}$. The distinction between the GFAP $\alpha$ and GFAP $\delta$ isoforms favors the classification of astrocytomas, and the identification of LncRNAs such as H19, MALAT1, and POU3F3, related to high-grade malignant gliomas, can improve the classification and the evaluation of malignancy ${ }^{29}$

SND1 and RhoA are associated with poor prognosis, in contrast to TIP30 expression and ATRX loss, considered as better prognosis biomarkers.

The current treatment of the various glioma types mostly includes radiotherapy, surgical intervention, and chemotherapy. The use of each method depends on the severity of the tumor, and more advanced cases require a combined approach.

The choice of treatment is relevant to the patient's life quality. A current problem is the lack of specific therapies that should be developed for each glioma subtype.

Advances in the field of glioma biomarkers open a landscape of opportunities to find additional targets such as SND1 and TIP30, which can inhibit the growth of tumor cells. The study of LncRNAs is also a promising nascent route to improve glioma treatment.

\section{Conclusion}

Biomarkers have substantially contributed to improve the diagnosis, prognosis, and treatment of gliomas. The combination of traditional imaging methods with molecular markers such as IDH1 and IDH2 gene mutations, MGMT gene promoter methylation, and $1 p / 19 q$ codeletion considerably improves the effectiveness of statistical and histological methods that in most of the cases depend of the analyst's experience. SND1, GFAP $\alpha$, and GFAP $\delta$ are three recently found promising biomarkers to improve diagnosis. TIP30 protein expression and ATRX gene deletion denote a favorable prognosis, and both are potential therapeutic targets. LncRNAs should be examined to assess their use as glioma biomarkers.

\section{Conflicts of interest}

The authors declare no conflicts of interest.

\section{Funding}

The authors received no specific funding for this work.

\section{Acknowledgements}

AFAG received scholarships from Consejo Nacional de Ciencia y Tecnología (Mexico) and Instituto Potosino de Investigación Científica y Tecnológica.

\section{Ethical disclosures}

Protection of human and animal subjects. The authors declare that no experiments were performed on humans or animals for this study.

Con $\nabla$ dentiality of data. The authors declare that no patient data appear in this article.

Right to privacy and informed consent. The authors declare that no patient data appear in this article.

\section{References}

1. Ostrom QT, Gittleman H, Truitt G, Boscia A, Kruchko C, Barnholtz-Sloan JS. CBTRUS statistical report: primary brain and other central nervous system tumors diagnosed in the United States in 2011-2015. Neuro Oncol. 2018;20:1-86.

2. Ostrom QT, Cioffi G, Gittleman H, Patil N, Waite K, Kruchko C, et al CBTRUS statistical report: primary brain and other central nervous system tumors diagnosed in the United States in 2012-2016. Neuro Oncol. 2019;21:1-100.

3. Reifenberger G, Blümcke I, Wesseling P, Pietsch T, Paulus W. Pathology and classification of tumors of the central nervous system. In: Oncology of CNS Tumors. Cham: Springer International Publishing; 2019. p. 3-89.

4. Van Bodegraven EJ, Van Asperen JV, Robe PA, Hol EM. Importance of GFAP isoform-specific analyses in astrocytoma. Glia. 2019;67:1417-33.

5. Li Y, Cai B, Chen S, Fu X, Pang X, Zhu X, et al. Overexpression of tat-interacting protein 30 inhibits the proliferation, migration, invasion and promotes apoptosis in bladder cancer cells. J Cancer Res Ther. 2018; 14:S713-8.

6. Wesseling $P$, Kros JM, Jeuken JW. The pathological diagnosis of diffuse gliomas: towards a smart synthesis of microscopic and molecular information in a multidisciplinary context. Diagn Histopathol. 2011;17:486-94.

7. Buckner JC. Factors influencing survival in high-grade gliomas. Semin Oncol. 2003;30:10-4.

8. Ghotme KA, Barreto GE, Echeverria V, Gonzalez J, Bustos RV, Sanchez M, et al. Gliomas: new perspectives in diagnosis, treatment and prognosis. Curr Top Med Chem. 2017;17:1438-47.

9. Farias-Eisner G, Bank AM, Hwang BY, Appelboom G, Piazza MA, Bruce SS, et al. Glioblastoma biomarkers from bench to bedside: advances and challenges. Br J Neurosurg. 2012;26:189-94.

10. Li Y, Shan X, Wu Z, Wang Y, Ling M, Fan X. IDH1 mutation is associated with a higher preoperative seizure incidence in low-grade glioma: a systematic review and meta-analysis. Seizure. 2018;55:76-82.

11. Wesseling P, Capper D. WHO 2016 classification of gliomas. Neuropathol Appl Neurobiol. 2018;44:139-50.

12. Wu S, Li J, Cao M, Yang J, Li YX, Li YY. A novel integrated gene coexpression analysis approach reveals a prognostic three-transcription-factor signature for glioma molecular subtypes. BMC Syst Biol. 2016;10:71.

13. Siegal T. Clinical relevance of prognostic and predictive molecular markers in gliomas. Adv Tech Stand Neurosurg. 2016;43:91-108.

14. Thon N, Tonn JC, Kreth FW. The surgical perspective in precision treatment of diffuse gliomas. Onco Targets Ther. 2019;12:1497-508.

15. Louis DN, Perry A, Reifenberger G, von Deimling A, Figarella-Branger D, Cavenee WK, et al. The 2016 World Health Organization classification of tumors of the central nervous system: a summary. Acta Neuropathol. 2016;131:803-20.

16. Yu J, Shi Z, Lian Y, Li Z, Liu T, Gao Y, et al. Noninvasive IDH1 mutation estimation based on a quantitative radiomics approach for grade II glioma. Eur Radiol. 2017;27:3509-22.

17. Strimbu K, Tavel JA. What are biomarkers? Curr Opin HIV AIDS. 2010:5:463-6.

18. Booth TC, Williams M, Luis A, Cardosa J, Keyoumars A, Shuaib H, et al. Machine learning and glioma imaging biomarkers. Clin Radiol. 2020; 75:20-32. 
19. Hu Y, Chen F, Liu F, Liu X, Huang N, Cai X, et al. Overexpression of TIP30 inhibits the growth and invasion of glioma cells. Mol Med Rep. 2016;13:605-12.

20. Fraser AR, Bacci B, le Chevoir MA, Long SN. Isocitrate dehydrogenase 1 expression in canine gliomas. J Comp Pathol. 2018;165:33-9.

21. Wiestler B, Capper D, Holland-Letz T, Korshunov A, von Deimling A, Pfister SM, et al. ATRX loss refines the classification of anaplastic gliomas and identifies a subgroup of IDH mutant astrocytic tumors with better prognosis. Acta Neuropathol. 2013;126:443-51.

22. Hegi ME, Diserens AC, Gorlia T, Hamou MF, De Tribolet N, Weller M, et al. MGMT gene silencing and benefit from temozolomide in glioblastoma. N Engl J Med. 2005;352:997-1003.

23. Reifenberger J, Reifenberger G, Liu L, James CD, Wechsler W, Collins VP. Molecular genetic analysis of oligodendroglial tumors shows preferential allelic deletions on 19q and 1p. Am J Pathol. 1994;145:1175-90.

24. Yu L, Xu J, Liu J, Zhang H, Sun C, Wang Q, et al. The novel chromatin architectural regulator SND1 promotes glioma proliferation and invasion and predicts the prognosis of patients. Neuro Oncol. 2019;21:742-54.
25. Porter AP, Papaioannou A, Malliri A. Deregulation of Rho GTPases in cancer. Small GTPases. 2016;7:123-38.

26. Stassen OM, van Bodegraven EJ, Giuliani F, Moeton M, Kanski R, Sluijs JA, et al. GFAP $\delta / G F A P \alpha$ ratio directs astrocytoma gene expression towards a more malignant profile. Oncotarget. 2017;8:88104-21.

27. Yu X, Li Z, Wu WK. TIP30: a novel tumor-suppressor gene. Oncol Res. 2015;22:339-48.

28. Gibbons RJ, Wada T, Fisher CA, Malik N, Mitson MJ, Steensma DP, et al. Mutations in the chromatin-associated protein ATRX. Hum Mutat. 2008;29:796-802.

29. Kiang KM, Zhang XQ, Leung GK. Long non-coding RNAs: the key players in glioma pathogenesis. Cancers (Basel). 2015;7:1406-24.

30. Louis D, Ohgaki H, Wiestler O, Cavenee W. WHO Classification of Tumors of the Central Nervous System. $4^{\text {th }}$ ed. Lyon, France: IARC Press; 2016. Available from: https://www.publications.iarc.fr/Book-And-ReportSeries/Who-larc-Classification-Of-Tumours/Who-Classification-Of-Tumours-Of-The-Central-Nervous-System-2016. 